\title{
Miracles de Notre-Dame par personnages, tome I, traduction de G. Bezançon et P. Kunstmann, Introduction de F. Paradis
}

\section{Piero Andrea Martina}

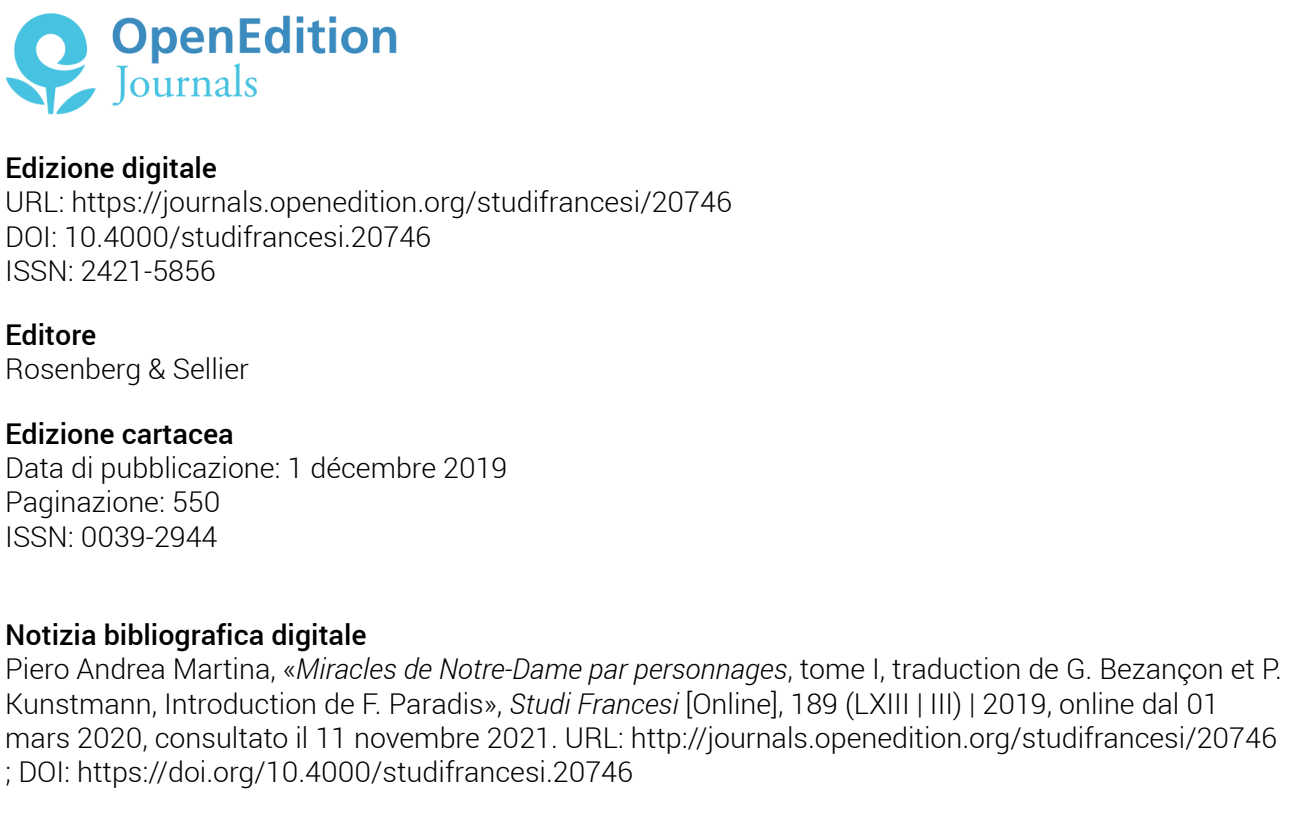

Questo documento è stato generato automaticamente il 11 novembre 2021.

\section{(ब) $\odot \Theta \Theta$}

Studi Francesi è distribuita con Licenza Creative Commons Attribuzione - Non commerciale - Non opere derivate 4.0 Internazionale. 


\title{
Miracles de Notre-Dame par personnages, tome I, traduction de G. Bezançon et P. Kunstmann, Introduction de F. Paradis
}

\author{
Piero Andrea Martina
}

\section{NOTIZIA}

Miracles de Notre-Dame par personnages, tome I, traduction de G. Bezançon et P. Kunstmann, Introduction de F. Paradis, Paris, Classiques Garnier, 2017, «Moyen Âge en traduction» 6, $714 \mathrm{pp}$.

1 Il ms. Cangé (BnF, fr. 819-820) è un oggetto a suo modo unico, nella misura in cui ci conserva una serie di quaranta miracles all'onore della Vergine, composti per la confraternita Saint-Éloi degli orfêvres di Parigi, rappresentati uno all'anno tra il 1339 e il 1382 , con alcune interruzioni. Ripresa in forma scenica semplice - e corta - di temi già presenti per esempio in raccolte narrative precedenti (Vie des [anciens] pères, Gautier de Coincy), la totalità dei Miracles del ms. Cangé si legge ancora nell'edizione storica di Gaston Paris e Ulysse Robert (Paris, SATF, 1876-1893, 8 voll.), nonostante alcune edizioni di singole pièces. È sul testo Paris-Robert che hanno lavorato i due traduttori, ottimi conoscitori dei testi in questione, G. Bezançon e P. Kunstmann, riprendendo alcuni materiali già preparati dallo stesso Kunstmann (per i miracles I e VII).

La traduzione, che si prevede in tre volumi, si propone di rendere pienamente accessibili i testi, corredandoli con un sistema di didascalie teatrali (desunte dal contesto e dalle battute stesse), che potrebbero anche ispirare eventuali rielaborazioni sceniche moderne. Apre il primo volume un'introduzione generale, il cui taglio denuncia l'apertura di questa pubblicazione - e della collana che arricchisce - a un pubblico più vasto di quello universitario. 
3 Ogni miracle - sono qui tradotti i miracles I-XVI - ha una propria succinta introduzione (opera di Fr. Paradis), che forse sarebbe potuta essere l'occasione per fornire una bibliografia specifica per il testo in questione, al di là dei titoli sporadicamente citati.

4 Chiude il volume una bibliografia dei titoli di cui si fa menzione in questo t. I, un indice dei nomi e dei luoghi presenti nei miracles tradotti. 